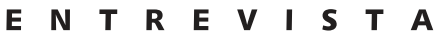

\title{
A Rica Experiência de Formação do e com o MST
}

Na perspectiva de uma maior concretude do projeto ético-político do Serviço Social no Brasil, tem havido nos últimos anos uma forte aproximação entre as unidades de formação profissional e os movimentos sociais, dentre os quais se

destaca o Movimento Nacional dos Trabalhadores Sem Terra - MST. Esse importante movimento tem desencadeado uma estratégia de formação de seus militantes e de outros movimentos sociais e, a partir disso, fundou a Escola Nacional Florestan Fernandes. Ali, os militantes tomam contato com um variado cardápio crítico de conteúdos que vão desde a teoria social, o entendimento do modo de produção capitalista, a formação social brasileira e suas particularidades, até discussões sobre o movimento e os processos de formação

da consciência. Contudo, essa estratégia vem passando também pelo estreitamento de laços com as universidades públicas, por meio muitas vezes do Serviço Social, criando cursos de graduação para turmas especiais, como na UFRJ, formadas por militantes dos movimentos. Nossa entrevista com Maristela Dal Moro e Geraldo Gasparin interpela dois protagonistas desse processo, na perspectiva de socializar a experiência e, sobretudo, de mostrar como a formação profissional em Serviço Social pode fortalecer os movimentos sociais.

Por Alba Tereza Barroso de Castro

\footnotetext{
* Maristela Dal Moro - doutora em Serviço Social pela Escola de Serviço Social da UFRJ, professora da ESS/UFRJ. Coordenadora do Curso dos Assentados da Reforma Agrária da ESS/UFRJ - Convênio UFRJ/INCRA-Pronera, em parceria com a Escola Nacional Florestan Fernandes e MST. Geraldo Gasparin - integrante da Comissão Pedagógica da Escola Nacional Florestan Fernandes (contribuiu com as respostas das questões 1 e 2).
} 
nevista all pautg

$\begin{array}{lllllllllll} & \mathbf{N} & \mathbf{T} & \mathbf{R} & \mathbf{E} & \mathbf{V} & \mathbf{I} & \mathbf{S} & \mathbf{T} & \mathbf{A}\end{array}$

EP: Contextualize o processo de construção da Escola Nacional Florestan Fernandes, situando as suas diretrizes e a concepção do seu Projeto de Formação.

Os primeiros passos na concretização da construção da Escola Nacional aconteceram no VIII Encontro Nacional do MST realizado em Salvador, BA, em janeiro de 1996, no qual participaram 180 delegados de 20 Estados. A construção propriamente dita teve início no ano 2000 e foi por meio de um processo não tradicional (solo-cimento), envolvendo o trabalho voluntário e a solidariedade, integrados a um programa de formação especialmente preparado para esse processo. Já trazia em si uma grande escola e colocava as brigadas em ligação direta com a construção física e a construção de seres humanos. Nesse sentido, a construção da escola significava uma escola em construção e pessoas em construção.

Neste sentido, a construção da ENFF representou, em todo esse processo, um símbolo da necessidade de ter o estudo como um valor, condição fundamental para a construção de um projeto alternativo, digno, solidário e humano e, sobretudo, para a emancipação da classe trabalhadora. Na relação com a sociedade, a ENFF se constituiu com a responsabilidade de ser um modelo da escola gratuita e de qualidade, cuja construção foi regida por quatro pilares/valores fundamentais: o estudo, a solidariedade, trabalho voluntário e a técnica alternativa de construção. Pilares que sustentaram e sustentam a estrutura física, política e pedagógica da ENFF.

A experiência desenvolvida na Escola resgata os valores da esquerda mundial e serve de referência para os movimentos e organizações que não perderam a esperança no futuro e, por isso, continuam construindo no presente as suas bases e os seus fundamentos de uma sociedade socialista.

A ENFF surge com o propósito de pensar, programar, planejar, organizar e desenvolver a formação política e ideológica dos militantes e dirigentes do conjunto do MST, independentemente dos setores e áreas de atuação. É a Escola de Formação de Quadros Políticos e, para tanto, deve primar pelo estudo científico e pela reflexão da prática política e organizativa dos membros e da organização - MST, e contribuir na elaboração de táticas e estratégias de ação nas diferentes áreas.

Portanto, a ENFF não é somente um espaço geográfico, tampouco uma estrutura física, mas é um conjunto de ações políticas e formativas/pedagógicas, que se desenvolvem no conjunto das atividades organizadas e realizadas pelo Movimento, independentemente do local e momento da sua realização.

EP: Fale sobre a estrutura e o funcionamento dos cursos da ENFF, mostrando a especificidade desta Escola em relação às clássicas Escolas de formação superior.

A ENFF se difere praticamente em tudo de uma escola clássica de formação superior. É uma escola de formação política e ideológica para o conjunto das lideranças dos movimentos sociais, independente do grau de escolaridade, e se fundamenta em uma proposta pedagógica e no conjunto de práticas educativas e formativas, no diálogo entre teoria e prática política. É uma escola que organiza sua própria autogestão envolvendo os educandos nos trabalhos domésticos, produtivos.

A ENFF está estruturada, organizada, a partir da constituição de cinco "Núcleos de Cursos": o Núcleo dos cursos de Teoria Política Latino-Americano, no qual estão todos os cursos voltados para o aprofundamento do pensamento latino- 


\section{ReVistg QIII PaUtd}

\section{E $\quad \begin{array}{llllllllll} & \mathbf{N} & \mathbf{T} & \mathbf{R} & \mathbf{E} & \mathbf{V} & \mathbf{I} & \mathbf{S} & \mathbf{T} & \mathbf{A}\end{array}$}

americano em várias áreas do conhecimento (economia política, filosofia, sociologia, teoria da organização, questão agrária, povos originários, método de trabalho de base, história da luta de classes de nosso continente, entre outros). O público-alvo destes cursos são jovens oriundos de organizações e movimentos sociais de todos os países da América Latina, Central e Caribe, tanto do campo como da cidade, e se dividem em três níveis de cursos que são: formação de formadores, formação política com ênfase na agitação e propaganda e, por fim, curso de pós-graduação para jovens universitários, já com a perspectiva de preparar os pesquisadores e formuladores da produção teórica, da sistematização das lutas, etc. O curso se realiza em convênio com a Universidade Federal de Juiz de Fora - MG

O segundo Núcleo é o de Teoria Política por temas livres e refere-se a todos os cursos realizados no espaço da ENFF e nos demais centros de formação espalhados por todo o território nacional que cumprem com a função de formação política para todos os níveis: base, militantes, dirigentes e quadros. São cursos específicos abrangendo diversos temas: marxismo, feminismo, comunicação, cultura, gênero, agroecologia, literatura, teatro, ecologia, etc.

Tem, ainda, os Núcleos Sindical e da Juventude. No primeiro, estão todos os cursos voltados à formação política do operariado das fábricas, estabelecendo, com isso, um diálogo mais próximo com esse segmento da classe trabalhadora e, no segundo, estão os cursos voltados à formação dos jovens do meio rural dos assentamentos.

Finalmente tem o Núcleo dos Cursos Formais, que reúne todos os cursos de formação de nível superior, tanto em nível de graduação como pós-graduação, no qual está inserido o curso de Serviço Social. Além desse que foi implementado pela Escola de Serviço Social da UFRJ, a ENFF vem implementando, junto às Universidades, em diversos estados do país, cursos em diferentes áreas do conhecimento para atender a demanda do MST: Direito, Jornalismo, Veterinária, Pedagogia, Filosofia, Geografia, História, Ciências Agrárias, Letras, Licenciatura em Educação do Campo.

EP: Configure o mapa atual dos cursos de serviço social na ENFF, situando as diferenças e especificidades entre estes cursos e os cursos de serviço social das Universidades públicas brasileiras, quanto aos critérios de seleção, estrutura curricular e dinâmica de funcionamento.

Para iniciar, é preciso situar o projeto implementado na Escola de Serviço Social da UFRJ, uma iniciativa dessa Escola em parceria com a Escola Nacional Florestan Fernandes e o Movimento dos Trabalhadores Rurais Sem Terra - MST.

Como já apontado anteriormente, esse curso nasce da parceria da ENFF com as Universidades de diversas regiões do país dispostas a contribuir no processo de formação dos trabalhadores. Uma das iniciativas mais importantes decorrente dessa parceria é a inserção de jovens assentados em curso superiores, nas mais diversas áreas do conhecimento. Tem papel fundamental nessa relação o Programa Nacional de Educação na Reforma Agrária - PRONERA, vinculado ao Instituto Nacional de Colonização e Reforma Agrária - INCRA. Esse programa, criado em 1998, e regulamentado por meio de decreto somente em 2010, é responsável pelo financiamento 
nevistg QIII pautg

\section{E $\quad \begin{array}{lllllllll}\mathbf{N} & \mathbf{T} & \mathbf{R} & \mathbf{E} & \mathbf{V} & \mathbf{I} & \mathbf{S} & \mathbf{T} & \mathbf{A}\end{array}$}

dos projetos de criação de turmas especiais de assentados, por meio de convênio com as Universidades. Importa ressaltar que o PRONERA é uma política pública de educação do campo desenvolvida nas áreas de Reforma Agrária e é expressão e produto de um amplo processo de organização e luta pela educação que se inicia ainda na década de 80. A sua elaboração e implementação, na década de 90 , ocorreu com a intensa participação de Universidades públicas e dos movimentos sociais que, unidos no propósito de enfrentar o analfabetismo no campo e romper com o monopólio cultural, propuseram um modelo de educação democrático e coerente com as demandas dos trabalhadores do campo. Desde então, milhares de jovens e adultos, trabalhadores das áreas de Reforma Agrária, têm garantido o direito de continuar os estudos em diferentes níveis de ensino. Os dados do INCRA apontam que aproximadamente 48.700 jovens provenientes do meio agrário tiveram oportunidade de ingressar no ensino superior, após a criação do PRONERA.

Em relação à turma especial de Serviço Social para assentados da reforma agrária da ESS, como já mencionado, se consolida por meio do convênio com o INCRA e com a Escola Nacional Florestan Fernandes e o MST.

É importante frisar que essa turma se constitui na sua maioria de militantes basicamente do MST, mas estão também representados a Via Campesina, o Movimento de Mulheres do Campo e o Movimento de Pequenos Agricultores (MPA). Precede a isso a condição de acampado ou assentado em projetos de reforma agrária, critério indispensável para ser reconhecido como beneficiário do PRONERA, por parte do INCRA. A constituição dessa turma de estudantes de Serviço Social, portanto, se adequou a esse critério e a seleção se restringiu ao público dos projetos de reforma agrária. Foram selecionados, para compor essa turma especial, 60 trabaIhadores provenientes de assentamentos e acampamentos da reforma agrária, de 19 estados do Brasil. Vale ressaltar a heterogeneidade dessa turma, a começar pela faixa etária, pois temos alunos na faixa de 17 anos até 50 anos. Outro fator importante é a trajetória desses trabalhadores. Se alguns estão iniciando sua trajetória de vida, trabalho e militância, temos outros que já percorreram um longo caminho e trazem à Universidade suas experiências, servindo de referência para os demais estudantes do curso de Serviço Social. Embora a sua prematura inserção na Escola de Serviço Social, pois o curso iniciou no primeiro semestre de 2011, várias iniciativas protagonizadas por esses alunos têm possibilitado a integração com o curso e com os demais estudantes; e a expectativa é que nos próximos semestres haja um fortalecimento dessa integração.

A grande novidade nessa proposta, à qual a Escola de Serviço Social precisou se adequar, é a forma de organização do curso, que tem como referencia a "Pedagogia da Alternância", que consiste em uma metodologia de organização do ensino constituída por dois tempos educativos: Tempo Escola e Tempo Comunidade. A ideia básica é conciliar o estudo e o trabalho na lavoura da família. Pode-se dizer que essa metodologia procura combinar, no processo de formação do jovem agricultor, períodos de vivência na escola com tempos transcorridos no meio familiar. Alternase, assim, a formação agrícola na propriedade, a sua inserção na militância com a formação teórica geral na escola que, além das disciplinas básicas, engloba uma preparação para a vida associativa e comunitária. 


\section{AeVistg QIII PaUtd}

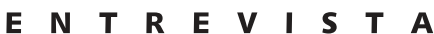

No projeto do curso de Serviço Social, o Tempo Escola acontece em dois meses a cada semestre. Os alunos permanecem no Rio de Janeiro durante esse período, quando frequentam as aulas das disciplinas e participam de atividades tanto da Universidade como de outros espaços, na cidade. No tempo que permanecem na Universidade, têm cobertura do PRONERA e da própria Universidade, para hospedagem, alimentação, transporte e material didático, viabilizando, com isso, a sua permanência no curso. Findo esse tempo, retornam às suas comunidades e à sua militância para desenvolver tarefas que consolidem a prática a partir do conhecimento adquirido na Universidade. Podem, com isso, combinar o tempo que devem estar nos assentamentos e nas suas comunidades, trabalhando, e o tempo que devem dedicar aos estudos, na Universidade.

Organizar um curso cuja proposta pedagógica está ancorada na alternância de dois tempos educativos distintos, mas complementares, requer necessariamente reorganizar o projeto pedagógico, tendo em conta essas etapas com tempo e espaços distintos. Na ESS, no que se refere às disciplinas, não foram feitas modificações em nenhum aspecto essencial, apenas foram rearrumadas, respeitando todos os pré-requisitos. O aluno da turma especial receberá exatamente a mesma formação que os alunos que ingressam habitualmente no curso regular de Serviço Social. No decorrer de cinco anos, os estudantes frequentarão o curso cumprindo todas as disciplinas do currículo da ESS, inclusive as disciplinas teórico-práticas, como o estágio. No período que permanecerem na Universidade, deverão inserir-se em pesquisas e em projetos de extensão, para que tenham garantido todos os requisitos para a sua formação na área. Estão previstas algumas disciplinas eletivas que deverão contemplar temáticas de interesse do grupo. A discussão acerca da questão agrária e dos movimentos sociais deverá ser transversal ao currículo e será tratada em várias disciplinas para fortalecer o debate e dar maior clareza a questões relativas ao mundo rural e à luta dos trabalhadores do campo. Por outro lado, alterações na organização do curso estão sendo feitas para atender a proposta de alternância. Buscou-se adequar o conteúdo das disciplinas de forma que cumpram a carga horária no decorrer dos dois meses do Tempo Escola. O fato de esse curso congregar militantes, principalmente do MST, traz uma dinâmica bastante particular. Para os estudantes desse curso, o tempo de permanência na Universidade não significa um rompimento com sua condição de militante. Nesse período, participam de várias atividades realizadas pelos movimentos sociais no Rio de Janeiro e organizam diversas atividades na própria Universidade, o que fortalece a relação da Escola com as lutas sociais. No decorrer do Tempo Comunidade, por sua vez, realizam várias atividades relativas aos conteúdos trabalhados na Universidade para complementar os seus estudos realizados no decorrer do Tempo Escola.

\section{EP: Aborde os processos de efetivação de parceria entre a Escola de Serviço Social da UFRJ e a ENFF, e de adequação da Escola da UFRJ à realização desse novo pro- jeto.}

A parceria da ESS com a ENFF vem se fortalecendo nos últimos anos e se consolidou muito em função da realização de projetos de extensão, que envolveram docentes e discentes da ESS. Vale a pena ressaltá-los. 
nevistg all pavtg

\section{E $\quad \begin{array}{lllllllll}\mathbf{N} & \mathbf{T} & \mathbf{R} & \mathbf{E} & \mathbf{V} & \mathbf{I} & \mathbf{S} & \mathbf{T} & \mathbf{A}\end{array}$}

O primeiro é o curso de extensão Teoria Social e Produção do Conhecimento, iniciado em 2004, coordenado inicialmente pelo Centro de Ciências Humanas (CFCH), e, em 2007, pelo Núcleo de Estudo em Políticas Públicas em Direitos Humanos (NEPP-DH), órgão suplementar ao CFCH. Esse curso, atualmente em sua terceira edição, conta com uma importante participação de professores da ESS, inclusive na coordenação, e de alunos, tanto da graduação como da pós-graduação, na condição de monitores.

O segundo teve início em 2006 e foi a experiência de estágio e extensão em áreas de acampamento e assentamentos da reforma agrária vinculadas ao MST. No decorrer de três anos de vigência desse projeto, aproximadamente 100 alunos do curso de Serviço Social realizaram estágio em áreas de reforma agrária. Ampliouse, com isso, o diálogo com esse Movimento e fortaleceu-se o estudo e pesquisa em temáticas derivadas dessas experiências, principalmente no que se refere à questão agrária e aos movimentos sociais; e estreitou-se ainda mais a parceria entre a ESS, o MST e a ENFF.

Tais projetos foram fundamentais nessa interlocução da ESS com a Escola Florestan Fernandes e o MST, mas não se encerra neles. Essa parceria vem se fortalecendo consideravelmente, nos últimos anos, principalmente em função da afinidade político-ideológica de segmentos do quadro docente da ESS com os princípios da ENFF e MST, levando muitos deles a contribuir com os projetos implementados pela ENFF. A criação dessa turma especial de Serviço Social é uma entre outras iniciativas que tem como objetivo contribuir para o fortalecimento da organização política dos trabalhadores e fortalecer, como isso, um projeto de esquerda e de radicalização democrática. Coerentes, o forte debate crítico presente no interior da categoria e esses docentes da ESS vêm construindo outras proposta de formação acadêmica e política em parceria com essa Escola, o que fortalecerá ainda mais essa parceria.

EP. No balanço que a Escola de Serviço Social da UFRJ faz da experiência de parceria com a ENFF, fale sobre as dificuldades encontradas e os impactos dessa sobre a própria unidade de ensino.

Embora façamos a avaliação extremamente positiva dessa experiência, temos absoluta clareza das dificuldades que teremos para concretizar esse projeto e por isso é importante tratá-lo inserido na dinâmica que é hoje a Universidade brasileira. Experiências como essas andam na contramão do movimento de privatização do ensino superior e das universidades públicas. Em um tempo de ampliação sem medida do ensino privado e dos cursos à distância, a constituição dessa turma de trabalhadores do campo soa de forma dissonante e será um grande desafio para a ESS, visto que curso fortalece uma concepção de Universidade pública e democrática.

O fato de essa proposta estabelecer um vínculo orgânico com os movimentos sociais, mais especificamente com o MST, traz à tona algumas divergências de fundo político-ideológico que, se não comprometeram o andamento do processo, colocaram algumas entraves ao seu pleno desenvolvimento. Convertidas, muitas vezes, em questões de ordem burocrático-administrativas ou acadêmicas, as divergências explicitam concepções distintas do papel da Universidade, prevalecendo, em al- 
neVistg aII pautg

\section{E $\begin{array}{lllllllllllll} & \mathbf{N} & \mathbf{T} & \mathbf{R} & \mathbf{E} & \mathbf{V} & \mathbf{I} & \mathbf{S} & \mathbf{T} & \mathbf{A}\end{array}$}

gumas análises, uma visão elitista, disciplinadora e burocratizada dessa instituição. Sem dúvida que esse projeto acirra as divergências e demonstra que a Universidade é um campo de disputas entre projetos distintos. A democratização do acesso ao ensino superior e a possibilidade de entrada de trabalhadores do campo, objetivos desse curso, fortalecem um projeto de Universidade mais democrática e participativa, condição fundamental para a socialização do saber e o fortalecimento dos interesses da classe trabalhadora.

Outro grande desafio dessa proposta refere-se ao próprio Serviço Social. Se esse projeto está completamente afinado com os princípios que constituem o projeto ético-político da profissão, isso não significa que não existem e existirão mais ainda resistências a essa proposta. O histórico conservadorismo que assola a profissão e que se aprofunda nos anos atuais, em decorrência da vinculação de profissionais aos projetos societários altamente regressivos, fere radicalmente os fundamentos críticos da profissão e pode se tornar um grande desafio na consecução desse projeto. Essa onda conservadora que atinge o Serviço Social se opõe teórica e politicamente aos fundamentos dessa proposta e poderá se transformar em uma forte oposição na medida em que esse projeto se fortaleça e ganhe visibilidade no Serviço Social.

Por outro lado, temos que ressaltar esse projeto nasceu fortalecido visto que contou com forte apoio de vários segmentos da profissão e outros setores da sociedade. No interior da Universidade, houve forte apoio de várias instâncias, entre elas pode-se mencionar o Centro de Ciências Humanas - $\mathrm{CFCH}$, a reitoria que deu suporte tanto financeiro quando político-acadêmico a essa proposta, e a direção da Escola de Serviço Social, bem como segmentos do seu quadro docente. A experiência em foco está profundamente afinada com a concepção de Universidade defendida pela ESS e o seu sucesso significa a consolidação dos princípios defendidos nessa gestão da Escola. Vale mencionar que um segmento docente e discente da Escola de Serviço Social foi protagonista na oposição a um modelo de expansão imposta pelo REUNI, expressão maior do sucateamento e precarização da Universidade pública. A criação dessa turma especial de assentados da reforma agrária garante a expansão da Universidade e resguarda a sua função social de democratizar o acesso à educação, bem como preserva a qualidade do ensino, resguardando os princípios que orientam o projeto de formação profissional do Serviço Social e os propósitos da Escola Florestan Fernandes.

Levanta-se, aqui, mais um ponto forte dessa proposta e que está referido ao movimento social como sujeito coletivo e partícipe desse processo. A sua presença na Universidade significa a entrada coletiva de sujeitos do campo. Em um tempo de grandes disputas, no interior das universidades, o ingresso dessa turma na Escola de Serviço Social fortalecerá um projeto educacional democrático e emancipatório, consoante com os princípios defendidos por essa Escola e pelo Serviço Social. Ainda é cedo para avaliar, pois o projeto iniciou esse ano, mas é possível afirmar de que para a Escola de Serviço Social essa turma trará ganhos enormes.

\section{EP: Qual o impacto dessa experiência no Serviço Social brasileiro?}

A experiência em questão, de formação de uma turma especial de Serviço Social para trabalhadores do campo e militantes dos movimentos sociais, é a primeira 


\section{ReVistg QIII PaUtd}

\section{E $\quad$ N}

de outras que virão. Sabe-se que outras Universidades vêm investindo na constituição desse projeto, no Serviço Social. Certamente que essas iniciativas terão grande impacto no âmbito do Serviço Social brasileiro. Primeiro, pois essas propostas devem fortalecer os princípios que constituem o projeto ético-político da profissão. Afirmase isso, pois o projeto profissional que se opõe à lógica imposta pelo mercado capitalista e se pauta em princípios emancipatórios ganha força com essa proposta de educação muito diferente da concepção hegemônica voltada para formação para o mercado de trabalho servindo, com isso, aos interesses do capital.

Expressa-se, nesse projeto, os princípios resguardados pela Escola Florestan Fernandes e pelo MST, que defendem que a educação deve contribuir para a transformação da sociedade atual, bem como para a construção de uma nova ordem social baseada nos pilares da justiça social, na radicalidade democrática e nos valores humanistas e socialistas. Esses princípios que orientam, também, o projeto do Serviço Social serão profundamente fortalecidos com a implementação e ampliação dessa proposta, que se opõe aos projetos profissionais conservadores. Para isso são fundamentais, também, as vozes dos estudantes desse curso que, embora provenientes de diversas regiões do país, trazem as mesmas expectativas e projetos reavivados em suas experiências de vida, trabalho e militância.

Sem dúvida que esse projeto e os outros que virão incidirão diretamente nos rumos do Serviço Social. A revalorização da luta coletiva, a defesa da coisa pública, da militância, tanto nos espaços das entidades da categoria como nas lutas mais gerais, nas quais os assistentes sociais historicamente tem se envolvido, serão fortalecidos a partir da implementação desses projetos. Acredita-se que no âmbito da pesquisa também haverá grande contribuições. Temas um tanto esquecidos nos estudos e pesquisas, tais como questão agrária, movimentos sociais e outros que derivam desses grandes temas, serão reavivados no interior da categoria; o que nos leva a afirmar que esse projeto poderá contribuir com o fortalecimento da integração da graduação com a pós-graduação. 